\title{
Perceptual Learning of Dysarthric Speech: A Review of Experimental Studies
}

Stephanie A. Borrie, BSLT $\left(1^{\text {st }} \text { Class }\right)^{1,2}$, Megan J. McAuliffe, $\mathrm{PhD}^{1,2}$, Julie M. Liss, $\mathrm{PhD}^{2,3}$

${ }^{1}$ Department of Communication Disorders, University of Canterbury, Private Bag 4800,

Christchurch, New Zealand

${ }^{2}$ New Zealand Institute of Language, Brain and Behaviour, University of Canterbury, Private Bag 4800, Christchurch, New Zealand

${ }^{3}$ Department of Speech and Hearing Science, Arizona State University, Box 870102, Tempe,

Arizona 85257-0102

Correspondence addressed to:

Stephanie Borrie, Department of Communication Disorders, University of Canterbury,

Private Bag 4800, Christchurch, New Zealand

E-mail: stephanie.borrie@pg.canterbury.ac.nz

Telephone: +64 33642431 Ext: 3524

Fax: +64 33642431

This is an author-produced manuscript that has been peer reviewed and accepted for publication in the Journal of Speech, Language, and Hearing Research (JSLHR). As the "Papers in Press" version of the manuscript, it has not yet undergone copyediting, proofreading, or other quality controls associated with final published articles. As the publisher and copyright holder, the American Speech-Language-Hearing Association (ASHA) disclaims any liability resulting from use of inaccurate or misleading data or information contained herein. Further, the authors have disclosed that permission has been obtained for use of any copyrighted material and that, if applicable, conflicts of interest have been noted in the manuscript. 


\begin{abstract}
Purpose: This review article provides a theoretical overview of the characteristics of perceptual learning, reviews perceptual learning studies that pertain to dysarthric populations, and identifies directions for future research that consider the application of perceptual learning to the management of dysarthria.

Method: A critical review of the literature was conducted that summarized and synthesized previously published research in the area of perceptual learning with atypical speech. Literature related to perceptual learning of neurologically degraded speech was emphasized with the aim of identifying key directions for future research with this population. Conclusions: Familiarization with unfamiliar or ambiguous speech signals can facilitate perceptual learning of that same speech signal. There is a small, but growing body of evidence that perceptual learning also occurs for listeners familiarized with dysarthric speech. Perceptual learning of the dysarthric signal is both theoretically and clinically significant. In order to establish the efficacy of exploiting perceptual learning paradigms for rehabilitative gain in dysarthria management, research is required to build on existing empirical evidence and develop a theoretical framework for learning to better recognize neurologically degraded speech.
\end{abstract}




\section{INTRODUCTION}

Dysarthria, a neurological disorder of the motor speech system, manifests itself in perceptual disturbances that compromise the integrity of the acoustic signal. It commonly results in impaired speech intelligibility. Indeed, intelligibility disturbances have been classified a "hallmark" feature of this speech disorder (Tikofsky \& Tikofsky, 1964; Yorkston, Beukelman, \& Bell, 1988) and described as "the most clinically and socially important aspects of dysarthria" (Ansel \& Kent, 1992, p. 296). As such, treatments that address improving speech intelligibility are fundamental to the successful management of dysarthria.

Speech intelligibility has traditionally been viewed as a property of the speaker (e.g., Black, 1957; Bond \& Moore, 1994; Hood \& Poole, 1980). Accordingly, dysarthria management has focused primarily upon individual speakers themselves, with emphasis on attempts to improve speech production or equip speakers with strategies or devices to compensate for their impairments (Duffy, 2005). Recent Cochrane reviews have concluded that there are no high-level studies to support or refute the efficacy of speech treatment for progressive and non-progressive dysarthrias (Deane, Whurr, Playford, Ben-Shlomo, \& Clarke, 2009; Sellars, Hughes, \& Langhorne, 2007). Considering the clinical significance of improving intelligibility for individuals with dysarthria, it is critical that research continue to examine the outcomes of behavioural modification on speech production. However, the consideration and development of innovative new forms of treatment is also vital.

Speech intelligibility has been defined as "the accuracy with which a message is conveyed by a speaker and recovered by a listener" (Klasner \& Yorkston, 2005, p. 127), highlighting the influence of both speaker and listener in the construct of intelligibility. With this in mind, Liss (2007) proposed a novel remediation strategy for targeting the speech intelligibility impairments exhibited by individuals with dysarthria—specifically, that treatments focus on the listener. The potential of a listener-targeted approach to the 
management of dysarthria should not be underestimated. Dysarthria very rarely occurs in isolation. Physical, cognitive and memory deficits frequently co-occur, all of which can greatly reduce the individual's capacity to learn and maintain benefits from speaker-oriented interventions (Duffy, 2005).Treatment that focuses on the neurologically intact listener (e.g., family members, friends, carers), thereby bypassing the speaker and any associated conditions that may adversely affect treatment gains, may prove key to optimizing communication success in those with dysarthria.

The notion of improving a listener's ability to understand the speech of individuals with dysarthria is theoretically based in the broader field of perceptual learning. When applied to speech, perceptual learning describes experience-evoked adjustments to the cognitive-perceptual processes required to recognize spoken language. In brief, these perceptual processes-lexical segmentation, lexical activation, and lexical competitionenable the listener to segment a continuous speech stream into individual words (lexical segmentation), to access the lexical items that may match these targets (lexical activation), and to select the most appropriate word for the spoken utterance (lexical competition) (Jusczyk \& Luce, 2002). Subsequently, word meanings are accessed and comprehension of the utterance occurs in context. Put simply, perceptual learning implies that a listener learns to better recognize a speech signal that is initially difficult to understand.

The last decade has seen much research focused on experimental designs that evaluate perceptual learning of speech. There is now a considerable body of evidence regarding the perceptual benefit for listeners familiarized with an ambiguous or unfamiliar speech signal (e.g., time-compressed, noise vocoded, foreign-accented) (see Samuel \& Kraljic, 2009). Research has also begun to investigate this phenomenon with neurologically degraded speech. While the body of research is small, preliminary evidence suggests that perception of dysarthric speech may also improve with training (e.g., Liss, Spitzer, Caviness, \& Adler, 
2002; Tjaden \& Liss, 1995a). This highlights the potential for perceptual learning to be exploited for rehabilitative gain in dysarthria management. However, if this is to occur, a considerable amount of research is first required. This research must build on existing empirical evidence and develop a theoretical framework for a perceptual learning approach to the treatment of dysarthria.

The purpose of this review is threefold, to: (i) define perceptual learning and provide an overview of the characteristics of learning within the broader category of atypical speech ${ }^{1}$; (ii) summarize and synthesize research that has examined perceptual learning specifically with dysarthric populations; and (iii) identify future directions for this line of research with consideration of its potential role in addressing intelligibility impairments exhibited by individuals with dysarthria.

\section{PERCEPTUAL LEARNING OF ATYPICAL SPEECH}

Defined as "relatively long-lasting changes to an organisms perceptual system that improves its ability to respond to its environment and are caused by this environment" (Goldstone, 1998, p. 585), perceptual learning of speech refers to the experience-evoked capacity to retune or adapt the speech perception system. That is, when listeners are familiarized with a speech signal that is unfamiliar or ambiguous, they are able to modify their perceptual strategies for subsequent processing of the atypical speech (Samuel \& Kraljic, 2009). Based on interactive models of speech perception, it is proposed that an individual's perceptual system is flexible, and dynamically adjusts to match the information provided in the incoming signal (e.g., McClelland \& Elman, 1986).

\footnotetext{
${ }^{1}$ Perceptual learning is reviewed with respect to experimental studies that have examined manipulation of the listener experience (familiarization/training).
} 
The laboratory study of perceptual learning has revealed important information about the ways in which familiarization with atypical speech alters subsequent perception. At the phoneme level, it has been shown that perceptual shifts in phoneme category boundaries occur following experience with ambiguous tokens embedded within lexical contexts (e.g., Eisner \& McQueen, 2005, 2006; Kraljic \& Samuel, 2005, 2006; Maye, Aslin, \& Tanenhaus, 2008; Norris, McQueen, \& Cutler, 2003). For example, Norris et al. (2003) observed that when Dutch listeners were trained with an ambiguous phoneme (acoustically and perceptually halfway between /s/ and /f/) in real or non-word contexts, listeners were able to extend the boundaries of one of their internal fricative categories $(/ \mathrm{s} /$ or $/ \mathrm{f} /)$ to include the ambiguous phoneme. That is, listeners' internal representations of the acoustic information constituting of /s/ or /f/ shifted to accommodate the ambiguous phoneme. The nature of the learning attributed to the phenomenon of category shifting has been termed perceptual adaptation, whereby training facilitates an acoustic-phonetic re-mapping of phonological information at the segmental level of perceptual processing (e.g., Eisner \& McQueen, 2005; Greenspan, Nusbaum, \& Pisoni, 1988).

Perceptual learning effects have also been reported as improvements in intelligibility (word recognition accuracy) with atypical speech following a familiarization experience. These unfamiliar or degraded acoustic signals can vary significantly along multiple phonetic and/or prosodic dimensions to that of typically encountered speech. Intelligibility improvements have been demonstrated in listeners who received training with foreignaccented (e.g., Bradlow \& Bent, 2008; Weill, 2001) and hearing-impaired speech (e.g., Boothroyd, 1985; McGarr, 1983), as well as artificially manipulated acoustic signals such as noise-vocoded (e.g., Davis \& Johnsrude, 2007; Davis, Johnsrude, Herrvais-Adelman, Taylor, \& McGettigan, 2005), computer-synthesised (e.g., Francis \& Nusbaum, 2009; Greenspan, et al., 1988; Nusbaum \& Lee, 1992), and time-compressed speech (e.g., Golomb, Peelle, \& 
Wingfield, 2007; Pallier, Sebastian-Galles, Dupoux, \& Christophe, 1998). As with phonemic category shift research, it is postulated that the source of perceptual benefit occurs primarily at the segmental level of perceptual processing. When listeners are exposed to the atypical speech pattern, the unique and systematic acoustic-phonetic characteristics of the atypical signal are mapped onto a listener's existing phonological space, causing a shift in perceptual representation of particular phonemes (e.g., Dupoux \& Green, 1997; Francis, Nusbaum, \& Fenn, 2007; Greenspan, et al., 1988). This shift is thought to benefit the cognitive-perceptual processes of speech perception, particularly lexical activation (e.g., reduced activation of a larger than necessary lexical cohort) and lexical competition (e.g., reduced competition for processing resources and increased likelihood of correct target selection), thereby yielding improved intelligibility.

Based on a number of findings, the most plausible account for these segmental benefits is that familiarization with the atypical signal induces an attentional shift toward more phonetically informative acoustic cues (e.g., Francis \& Nusbaum, 2000; Francis, et al., 2007; Nusbaum \& Goodman, 1994; Pisoni, Lively, \& Logan, 1994). According to this explanation, training does not increase the quality or the quantity of the available acoustic information, but rather directs cognitive resources to those cues considered most relevant for recognition of the unique signal. For example, Francis et al., (2000) provided empirical evidence that the provision of category-level feedback during training with synthetic speech provoked changes in the way in which place of articulation cues were exploited. More recently, Francis and Nusbaum (2009) observed a relationship between working memory and perceptual learning-listeners trained with synthetic speech were better able to utilize working memory for improved recognition of the atypical signal. If training does in fact improve the distribution of attentional resources (i.e., increased attention toward more 
informative cues at the expense of less relevant information), demands on working memory may decline, and improved recognition may result (Francis \& Nusbaum, 2009).

Perceptual learning research using time-compressed speech, a signal characterised by systematic manipulation to its temporal characteristics, has demonstrated that listeners may also learn something about the global prosodic features of the speech signal—specifically its rhythmic qualities—-that facilitates learning (Pallier, et al., 1998; Sebastian-Galles, Dupoux, Costa, \& Mehler, 2000). The mechanism for this learning may be described as rhythmic expectancy, whereby listeners can anticipate and focus attention on high-yield aspects of the signal when they have adapted to the systematically varied rate and rhythm. Sebastian-Galles and colleagues (2000) examined perceptual learning of time-compressed speech across different language classes with distinguishably different rhythmic patterns (syllable-timed vs. stress-timed vs. mora-timed). They found that perceptual learning outcomes were influenced by the rhythmic properties of the training signal. For example, familiarization with syllabletimed languages facilitated improved processing of other syllable-timed languages, but not with signals characterised by another rhythmic pattern. This suggests that acoustic-phonetic remapping is not the only source of benefit that underlies experience-evoked intelligibility improvements and that suprasegmental learning may facilitate subsequent lexical segmentation of speech with similar rhythmic structure.

Traditionally assumed to have limited relevance (e.g., Halle, 1985), a role for indexical information - extralingustic properties that index attributes specific to the speaker (Abercrombie, 1967)—in perceptual learning of speech has recently been acknowledged (e.g., Loebach, Bent, \& Pisoni, 2008). Nygaard and colleagues (1994) found that listeners trained to identify the names of ten unfamiliar speakers exhibited significantly greater recognition scores when presented with novel words produced by these same speakers relative to listeners presented with novel words produced by unfamiliar speakers. Similar 
perceptual benefits afforded by attention to indexical properties of the signal were observed with sentence-level recognition in a follow-up study (Nygaard \& Pisoni, 1998). Nygaard and Pisoni (1998) postulated that observations of improved linguistic processing following familiarization with the indexical elements of speech would suggest that similar cognitiveperceptual processes may underpin the learning of both types of information. More recently, Loebach et al., (2008) revealed that the perceptual benefit of training on indexical properties may also extend to the perception of the noise-vocoded speech signal. Listeners engaged in a speaker identification task made significant intelligibility gains and in addition, the gains were as great as those achieved by listeners engaged in a linguistic-based transcription training task. Thus, these studies yield preliminary evidence that indexical information may inform recognition of artificially degraded speech.

Taken together, it appears likely that multiple potential sources of perceptual learning exist (Sebastian-Galles, et al., 2000). While the evidence regarding learning sources and the relative contribution of different levels of information is limited, it may be presumed that familiarization with atypical speech enables listeners to extract something about the unusual regularities, and that this facilitates improved perceptual processing in subsequent encounters. Until now, this tutorial has treated "familiarization" or "training" with atypical speech in a rather nebulous way. However, the specific ways in which listeners receive training vary on a number of levels including familiarization material, familiarization conditions, and amount of familiarization. Such factors may or may not influence the longevity of learning and whether effects are generalized across stimuli and/or speakers. These characteristics of perceptual learning are discussed in turn.

Familiarization Material. Familiarization material describes the stimuli (usually speech) used to promote perceptual learning of the speech signal. Studies have reported that perceptual learning may be most robust when listeners are familiarized with real word, rather 
that nonword, stimuli (e.g., Davis, et al., 2005; McQueen \& Mitterer, 2005; Norris, et al., 2003). This suggests a lexical influence in perceptual learning of speech. When listeners were familiarized with an ambiguous phoneme embedded within word or nonword training material, category boundary shifts were identified only for those listeners trained with real words (Norris, et al., 2003). Using noise vocoded speech , a signal characterised by systematic manipulation to its spectral information, similar findings regarding the benefit of lexical information were reported (Davis, et al., 2005). Listeners exposed to sentences containing real words demonstrated improved word recognition of the noise vocoded speech, whereas a learning response was not identified for listeners exposed to a nonword sentence condition. When the familiarization material was further manipulated to remove sentencelevel or syntactic information, it was found that sentence-level meaning did not appear crucial to perceptual learning. Specifically, listeners familiarized with syntactic prose sentencesgrammatically correct sentences with real words but no sentence level meaning (e.g., the effect supposed to the consumer)—achieved similar perceptual learning effects as those of listeners presented with semantically coherent English sentences (Davis, et al., 2005). While this was the case, syntactic content alone did not appear to be the critical element behind perceptual learning. Listeners who were presented with jabberwocky sentences—sentences with real English function words but nonword content words (e.g., the tekeen garung to the sumeeun)—exhibited significantly less perceptual learning than listeners trained with sentences containing only real words. It was concluded that lexical information drove perceptual learning of noise vocoded speech. However, both word and non-word familiarization conditions facilitated improved word recognition of noise vocoded speech when exposure material compromised of individual words, as opposed to sentence-level stimuli previously employed (Hervais-Adelman, Davis, Johnsonrude, \& Carlyon, 2008). Thus lexical information may not be crucial to the facilitation of a perceptual learning response 
when the stimuli, as is the case with single words, can be accurately retained in short term memory.

Familiarization Conditions. A second issue relates to the provision, or otherwise, of feedback to augment the auditory stimuli during familiarization. That is, whether knowledge of the atypical productions is required for perceptual learning outcomes to be realized. The evidence on this issue is varied. McQueen et al. (2006) demonstrated that learning to categorize an ambiguous phoneme could be achieved with a simple auditory listening experience (passive familiarization). However, other studies have demonstrated that learning may necessitate more explicit familiarization, wherein listeners are provided with feedback about classification performance or written information regarding the intended lexical targets (e.g., Davis, et al., 2005; Fenn, Nusbaum, \& Margoliash, 2003). Learning of synthetic speech has been reported following passive experience with auditory stimuli (Koul \& Hester, 2006; Reynolds, Isaacs-Duvall, \& Haddox, 2002) and in studies that have employed a more explicit familiarization procedure (e.g., Greenspan, et al., 1988; Reynolds, Isaacs-Duvall, Sheward, \& Rotter, 2000; Schwab, Nusbaum, \& Pisoni, 1985). Studies comparing passive and explicit familiarization with noise-vocoded speech have reported superior learning when the degraded stimuli is supplemented with undistorted (auditory or written) versions of the spoken targets (Davis, et al., 2005; Loebach, Pisoni, \& Svirsky, 2010). In sum, it appears that perceptual learning may take place automatically when the learning entails subtle adjustments to an existing phonetic category distinction (e.g., Norris, et al., 2003). However, adaptation to an entirely novel category distinction (e.g., Logan, Lively, \& Pisoni, 1991) or to an acoustic signal with substantial acoustic degradation may require more explicit familiarization (e.g. Davis, et al., 2005; Fenn, et al., 2003). 
Amount of Familiarization. The amount of familiarization listeners are afforded has also varied substantial across studies. Extremely rapid learning effects have been observed following less than one minute of familiarization with natural changes in speech rate (e.g., Miller, 1981; Miller \& Liberman, 1979) and spectral degradations (e.g. Summerfield, Haggard, Foster, \& Gray, 1984; Watkins, 1981). Several minutes of familiarization enabled perceptual learning of time-compressed (Mehler et al., 1993; Pallier, et al., 1998) and foreignaccented speech (Bradlow \& Bent, 2008; Clarke \& Garrett, 2004); whereas, 25 minutes (Davis, et al., 2005), nine 20 minute sessions (Rosen, Faulkner, \& Wilkinson, 1999), and four sessions of one to two hours (Stacey \& Summerfield, 2007) of familiarization has been observed for learning to better recognize the noise-vocoded speech signal. Similar to the speculations made with familiarization conditions, as speech becomes increasingly degraded, longer periods of familiarization may be required for perceptual learning outcomes to be realized. While there is no conclusive evidence regarding the amount of familiarization needed to achieve learning, studies to date would suggest that learning occurs relatively quickly, even for severely distorted speech.

Longevity of Learning. It appears that once learning has occurred, it can remain stable over a period of time. Eisner and McQueen (2005) observed learning to categorize an ambiguous phoneme remained robust following a 25 minute time lapse-even when passive listening to speech (which did not contain the ambiguous phoneme) occurred during the delay period. Learning effects were also reported following a lapse of 12 hours and moreover, were not dependent upon the opportunity for consolidation during sleep (Eisner \& McQueen, 2005). In contrast, studies using synthetic speech have reported the need for sleep to maintain learning effects over a 12-hour period (Fenn, et al., 2003). Robust perceptual learning outcomes, measured in terms of vowel, consonant, word and sentence recognition were observed 7-15 days following familiarization with noise-vocoded speech (McGettigan, 
Rosen, \& Scott, 2008), and improved word recognition of synthetic speech was observed at a six months follow-up test task (Schwab, et al., 1985). While limited in terms of study numbers, preliminary evidence suggests that perceptual learning may not simply be a temporary adjustment to the listener's perceptual system. Rather, that learning of the unusual regularities within the acoustic signal is long-lasting and facilitates permanent perceptual change.

Generalization of Learning. Studies have also demonstrated that perceptual learning effects can generalize between lexical items (e.g., Davis, et al., 2005; Francis \& Nusbaum, 2000). McQueen et al., (2006) and Norris et al. (2003) observed detectable changes in the categorization of an ambiguous phoneme in words that differed from the targets encountered during the familiarization task. This learning transfer was taken as evidence that learning may transpire at the sublexical level. Generalization of learning to untrained words has also been reported in the recognition of accented speech (Clarke \& Garrett, 2004), noise-vocoded speech (Davis, et al., 2005; Hervais-Adelman, et al., 2008), and synthesized speech (Fenn, et al., 2003; Francis \& Nusbaum, 2000). Such findings further support the notion that perceptual representations may be modified, at least to some degree, at the level of the phonetic unit. While the evidence for learning transfer across novel lexical targets is relatively robust, the support for cross-speaker generalization is less conclusive. Eisner and McQueen (2005) found that perceptual learning of an ambiguous fricative did not generalize to a novel speaker (i.e., one not included in the training condition). In contrast, Kraljic and Samuel (2006) reported cross-speaker generalization for perceptual learning of an ambiguous stop phoneme. That phoneme learning generalized across speakers in some situations, but not in others, may indicate variations in the amount of speaker-specific information afforded by particular phoneme productions (Kraljic \& Samuel, 2006). Evidence of learning transfer across speakers has also been found in studies with foreign-accented speech (Bradlow \& Bent, 2008; 
Weill, 2001) and time-compressed speech (Dupoux \& Green, 1997; Kouider \& Dupoux, 2005), when the speakers exhibit similar speech patterns (i.e., speech modified in the same

manner). Finally, learning of vocoded speech has been found to generalize between acoustic characteristics (Dahan \& Mead, 2010; Hervais-Adelman, Davis, Taylor, Johnsrude, \& Carlyon, 2011). While complete learning was achieved between different frequency regions (low-pass and high-pass filtered signals), carry-over was limited between different carrier signals (noise bands, sine waves, and pulse trains) (Hervais-Adelman, et al., 2011) and stimuli with minimal phonetic similarity (Dahan \& Mead, 2010). Taken together, the findings suggest that the ability and extent to which learning can be generalized may be dependent on the acoustic similarity between the training and testing stimuli.

\section{PERCEPTUAL LEARNING OF DYSARTHRIC SPEECH}

As the preceding discussion has established, perceptual learning research using healthy speech variants (non-native) or laboratory modified speech (e.g., time-compressed or noise vocoded) presumes that listeners learn something about the regularities in atypical patterns and can apply that information to subsequent encounters with those atypical patterns. However, it is difficult to directly adopt this presumption when considering perceptual learning of dysarthric speech. The speech degradation that occurs in individuals with neurologic impairment is, by its nature, far from consistent. Speakers may deal with issues such as fluctuating muscle tone, inadequate respiratory support that worsens with fatigue, phonatory instability, and overarching deficits in articulatory movement coordination. Thus, while some acoustic features (e.g., hypernasality or breathiness) may be consistent and pervasive in a person's speech, others may vary widely (e.g., irregular articulatory breakdowns or variable speech rate). If we adopt the more general view of perceptual learning, we can hypothesize that those aspects of the degraded acoustic signal that are the 
most consistent and regular will be more "learnable"—and therefore more salient for improving perceptual performance-than those aspects which are inconsistently expressed. By extension, dysarthrias with more consistent signal degradations (e.g., hypokinetic) would be expected to be more amenable to perceptual training than those with more variability (e.g., hyperkinetic). However, the role of acoustic consistency in perceptual learning remains largely untested. It may very well be that there is perceptual learning value in exposure to non-systematic acoustic variation as well, even though the source of benefit could not be attributed to inducing a perceptual remapping. In this case, establishing "expectations of variability" may be the mechanism by which performance is enhanced. Recent work by Mattys and Liss (2008) has identified that words produced by a speaker with hypokinetic dysarthria were better recalled if played in the same voice, as opposed to a different voice, between the two successive blocks. This perceptual advantage of indexical consistency suggests that speaker-specific detail may inform recognition of dysarthric speech.

Investigations have yet to document whether indexical information influences perceptual learning of dysarthric speech. It is imperative to establish "what is learnable" if perceptual learning is to be harnessed to build a theoretical account that supports, or otherwise, the development of listener-based treatment for the management of dysarthria.

To date, only a handful of studies have examined perceptual processing and changes to speech recognition for listeners familiarized with dysarthric speech. These are reported in Table $1^{2}$. The majority of these studies have been clinically-based and their findings largely equivocal. While some research has observed significant intelligibility gains with a familiarization experience (D'Innocenzo, Tjaden, \& Greenman, 2006; Hustad \& Cahill, 2003;

\footnotetext{
${ }^{2}$ Relevant studies were identified by electronic databases searches of PsycINFO, MEDLINE, CINAHL, and PubMED. The searches comprised of keywords (e.g., perceptual learning, familiarization, adaptation) paired with the term dysarthria. In addition to these electronic searches, hand searches of studies cited within an article were conducted. From this large search, those citations in which listeners were familiarized with dysarthric speech were abstracted by the first author in Table 1 .
} 
Liss, et al., 2002; Spitzer, Liss, Caviness, \& Adler, 2000; Tjaden \& Liss, 1995a, 1995b), others have not (Garcia \& Cannito, 1996; Yorkston \& Beukelman, 1983). Substantial variations in research designs limit the degree to which studies can be compared; however, they do provide valuable insight into variables that may influence the nature of perceptual learning with the dysarthric signal. In the following section we summarize this body of research presented in Table 1 with regard to the possible source(s) of learning in the dysarthrias, and the variables that appear most salient in facilitating improved recognition of dysarthric speech.

Learning Source. Traditionally, the dysarthrias are categorized by both type and severity, dependent upon the presence of perceptual errors (segmental goodness) and patterns (e.g., speech rate and prosody, phonatory characteristics), and the degree to which these errors and patterns impact the integrity of the acoustic signal (Duffy, 2005). This conceptualization motivates the majority of studies of perceptual learning in dysarthria, wherein a wide variety of dysarthria types (flaccid, spastic, ataxic, hypokinetic, hyperkinetic, spastic-flaccid, spastic-hyperkinetic and spastic-ataxic) and severities (ranging from mild to severe) have been employed. Further, the few studies that have sought to identify a source of learning (i.e., "what is learnable?”) have approached dysarthric speech signal characteristics in terms of segmental versus suprasegmental degradation.

To our knowledge, the first attempt to address "what is being learned" in a case of dysarthria was conducted by Tjaden and Liss (1995a). A non-native English speaking woman with cerebral palsy and a moderate-to-severe spastic-ataxic dysarthria provided the speech material. Normal hearing listeners transcribed her speech after first being familiarized with either her production of a read passage or with all of the words of the passage presented as a single read word list. It was expected that experience with the segmental and suprasegmental features in the read passage would be superior for perceptual learning than the single words, 
but ultimately both conditions benefitted intelligibility to the same degree beyond a control condition. Additional analysis confirmed that listeners learned the non-native English regularities, such as substituting /1/ for $/ \mathrm{r} /$.

In subsequent work, Liss and colleagues attempted to develop dependent variables that would distinguish learning about segmental regularities from suprasegmental regularities. Liss et al. (2002) examined the lexical boundary error (LBE) patterns (errors that reflect a reliance on syllable stress contrasts to inform processes of lexical segmentation) of listeners familiarized with either ataxic or hypokinetic dysarthria. While all listeners made the anticipated post-familiarization intelligibility gains, LBE findings revealed no significant difference in error patterns made by familiarized listeners when compared with same signal transcriptions from nonfamiliarized listeners. It is possible that this result indicates that familiarization does not improve a listener's ability to perceive differences in syllable stress contrasts with ataxic or hypokinetic dysarthria. However, it is also possible that the familiarization procedure employed by the study, just 18 phrases, was too brief to facilitate detectable changes to the processes of lexical segmentation.

In a post-hoc exploration of these data, Spitzer et al. (2000) completed segmental error analysis of the listener transcripts of participants who received explicit familiarization using phrases produced by speakers with either ataxic or hypokinetic dysarthria. The study observed changes to segmental error patterns for listener's familiarized with ataxic speech but not for those familiarized with hypokinetic speech. Listeners who heard and transcribed ataxic stimuli produced a higher proportion of target consonants in word substitutions and a lower number of substitution errors that were not phonemically related to the intended targets compared to listeners who simply transcribed the ataxic speech stimuli. Interestingly, this segmental level benefit was not enjoyed by listeners who heard and transcribed hypokinetic speech. Absence of segmental level changes for listeners familiarized with hypokinetic 
speech provides further support for the hypothesis that the source of learning may be dependent upon type of dysarthria (Spitzer, et al., 2000). However, the type of analysis employed and, again, the fleeting familiarization procedure, must be considered. It is predicted that a more extensive familiarization procedure and a more elaborate multi-level analysis of listener transcripts may reveal a more comprehensive picture of the cognitiveperceptual changes associated with perceptual learning of dysarthric speech. Nonetheless, current findings enable us to speculate that the source of learning is likely influenced by the characteristics of the signal to be learned.

Signal Characteristics. The importance of type and quality of signal characteristics is further supported by a number of findings in the literature. Hustad and Cahill (2003) observed immediate improvements in recognition of mildly dysarthric speech for listeners familiarized with just 10 phrases of the speech, however at least 30 familiarization phrases were required for intelligibility gains to be realized with severely dysarthric speech . Consistent with these findings, Garcia and Cannito (1996) failed to report any intelligibility benefit for listeners who received a single 16 phrase familiarization experience with severe dysarthria. Thus, it could be hypothesised that learning to better understand severely degraded dysarthric speech may necessitate greater amounts of familiarization than that required to achieve learning of milder forms of dysarthria. When intelligibility scores of ataxic and hypokinetic speech stimuli were matched, Liss and colleagues (2002) found that perceptual benefits of familiarization were greatest for listeners who heard and transcribed phrases produced by the speakers with ataxic dysarthria. This suggests that the perceptual presentation of ataxic dysarthria may be more amenable to learning than that which characterizes hypokinetic dysarthria. Taken together, the small number of studies conducted thus far demonstrates that perceptual learning may be highly dependent upon the characteristics of the signal to be learned. While further investigation into the effect of signal 
type and severity on the intelligibility benefits afforded by a familiarization experience is warranted, existing literature reveals a likelihood that such a relationship exists.

Familiarization Conditions: To date, two types of familiarization conditions have been employed in studies that have examined perceptual learning of dysarthric speech: passive familiarization (degraded signal only), and explicit familiarization (degraded signal and written transcripts of the target stimuli). A clear picture of how different conditions enhance, or otherwise, learning outcomes when listeners are familiarized with dysarthric speech is yet to emerge (see Table 1). Some studies that have employed passive familiarization have reported intelligibility gains for familiarized listeners (Hustad \& Cahill, 2003); whereas others have observed no perceptual benefit following a simple auditory experience with the degraded signal (Garcia \& Cannito, 1996; Yorkston \& Beukelman, 1983). Similarly, when studies have utilized explicit familiarization involving both the degraded signal and written information, intelligibility gains have been documented in some studies (D'Innocenzo, et al., 2006; Liss, et al., 2002; Spitzer, et al., 2000; Tjaden \& Liss, 1995a) but not in others (Yorkston \& Beukelman, 1983). To date, the one study that directly compared intelligibility scores following passive versus explicit exposure reported no significant difference across the two familiarization conditions (Yorkston \& Beukelman, 1983).

Amount of Familiarization: Conflicting findings regarding the benefit of different familiarization conditions are likely due, in part, to the varying amount of familiarization undertaken. For example, listeners who failed to exhibit intelligibility gains following passive familiarization were exposed to a short conversational sample (specific details not provided) of dysarthric speech (Garcia \& Cannito, 1996). In contrast, passive familiarization to 40 phrases yielded significant perceptual gain for listeners (Hustad \& Cahill, 2003). From this comparison alone, it appears that when familiarization is passive, a greater amount of training 
may be required for the learning response to be realized. Studies that have employed explicit familiarization procedures indicate that amount of training may have less impact on the perceptual benefit of familiarization (see Table 1 for more details).

Listener Familiarity: Previously published studies that have reported intelligibility improvements for listeners familiarized with dysarthric speech have all employed listeners naïve to this type of speech degradation (e.g., D'Innocenzo, et al., 2006; Hustad \& Cahill, 2003; Liss, et al., 2002; Spitzer, et al., 2000). The single study that utilized speech pathologists and student clinicians as listeners failed to observe intelligibility improvements when familiarized with dysarthric speech under either passive or explicit conditions (Yorkston \& Beukelman, 1983). Thus, it could be speculated that the listeners in this study, presumed already familiar with dysarthric speech, had previously adapted to the degraded speech during unstructured interactions. Experimental studies on listeners familiarized with dysarthric speech have yet to investigate the role of listener familiarity in perceptual learning of dysarthric speech.

\section{DEVELOPING A PERCEPTUAL LEARNING APPROACH TO MANAGEMENT}

Taken together, the small number of studies conducted thus far yield preliminary evidence that listeners can learn to better recognise neurologically degraded speech. Moreover, the studies provide insight into the possible learning sources that enable these intelligibility improvements to be realised. Improved word recognition for listeners familiarized with dysarthric speech reveals a potentially promising avenue for future intervention - that is, using a perceptual learning approach to address the intelligibility impairments that debilitate this population. While such an approach may or may not afford clinical application to individuals already familiar with dysarthric speech, improving intelligibility for those unfamiliar with dysarthric speech, including family and friends of 
speakers with a recently acquired dysarthria (e.g., stroke, traumatic brain injury), holds significant value. Indeed the importance of research into listener training was underscored almost a decade ago (Yorkston, Dowden, \& Beukelman, 1992). In order to establish the efficacy of exploiting perceptual learning paradigms for rehabilitative gain in the management of dysarthria, a considerable amount of research is first required. In the subsequent section we outline the initial steps required to develop a theoretical framework upon which future listener-targeted, perceptual learning approaches to the treatment of dysarthria can be developed. As some patterns and degrees of acoustic degradation are likely more amenable to learning than others, research in all four areas outlined below should be explored with dysarthrias of varying types and severities under comparable experimental conditions.

As a primary step, the establishment of strong empirical evidence supporting the existence of a perceptual learning effect resulting from experience with dysarthric speech is required. While evidence of intelligibility improvements for listeners familiarized with dysarthric speech have been reported (D'Innocenzo, et al., 2006; Spitzer, et al., 2000), the absence of adequate experimental control has reduced the strength of existing findings. Research conducted thus far has attempted to assess the magnitude of perceptual learning effects by comparing intelligibility scores from listeners familiarized with dysarthric speech to nonfamiliarized listeners. In such cases, particularly where the training material affords similarities to the testing material, it is challenging to separate the perceptual improvements that result from familiarization with dysarthric speech, to those that may arise simply from the familiarization experience (e.g., Hustad \& Cahill, 2003; Liss, et al., 2002). In order to reliably attribute perceptual benefits to familiarization with dysarthric speech, research is required to include a control group, where listeners are familiarized with stimuli produced by neurologically intact speakers, age- and gender-matched to the speakers providing the 
dysarthric stimuli. Such comparisons would strengthen evidence of perceptual learning with dysarthric speech.

Once a perceptual learning effect has been established, a comprehensive picture of the cognitive-perceptual processes associated with improved recognition of the dysarthric signal is required. Common models of perceptual learning of speech assume an interactive integration of information, whereby bottom-up acoustic-phonetic information is supplemented with top-down linguistic and real world information (Francis, et al., 2007). From a theoretical vantage point, intelligibility improvements could arise from improved processing of any one, or combination, of the perceptual degradations that characterise dysarthria. To date, only two studies have begun to shed light upon the possible cognitiveperceptual changes associated with intelligibility benefits following familiarization with dysarthric speech. These studies have examined source of learning from a segmental versus suprasegmental perspective, and have proposed that the perceptual benefits associated with a familiarization experience may occur with improved processing of segmental information. However, evidence regarding the source of learning associated with improved recognition of dysarthric speech is limited and current findings have not led to a clear answer. In order to provide a more complete picture of the source of learning associated with improved recognition of neurologically degraded speech, large scale studies that consider the role of attentional mechanisms and resource allocation to linguistic (segmental and suprasegmental) and indexical features, with respect to both systematic and non-systematic degradation, are required. Such knowledge is not only key to a theoretical framework of perceptual learning of the degraded signal, but may further inform current models of perceptual processing with typical and atypical speech.

If high-level evidence regarding the perceptual benefit of familiarization with dysarthric speech is established and the source of such learning is identified, research must 
seek to determine the conditions required to achieve this learning. As previously stated, a significant methodological variation across the existing research is found in the type of familiarization conditions employed. There is evidence that learning may transpire automatically, as a result of passive familiarization to the degraded auditory productions (e.g., Hustad \& Cahill, 2003). There is also evidence to suggest that more explicit familiarization involving supplementary written information may be required for perceptual benefits of familiarization to be realized (e.g., Liss, et al., 2002). Existing research has yet to provide conclusive evidence on this matter. According, studies are needed to determine the conditions that promote improved recognition of dysarthric speech.

Clinically, the perceptual benefit of familiarization is only of functional value if improvements can persist over time. Therefore, research is also required to identify whether intelligibility improvements observed immediately following experience with dysarthric speech can remain stable over a period in which no further neurologically degraded speech input is received. While studies other forms of atypical speech have demonstrated that the intelligibility benefit following familiarization can continue following a significant time lapse (e.g., Lively, Pisoni, Yamada, Tohkura, \& Yamada, 1994; McGettigan, et al., 2008), the few studies that have examined perceptual learning with dysarthric speech have yet to investigate this phenomena. Bearing in mind the multiple segmental and suprasegmental distortions that characterise the dysarthric signal, improved recognition of dysarthric speech presumably involves a number of different processing levels and significant cognitive resources. Thus, investigation into the longevity of perceptual learning effects holds both clinical and theoretical significance. 


\section{SUMMARY}

The potential for perceptual learning of the dysarthric signal is considerable. If familiarization with dysarthric speech could facilitate improvements in a listener's ability to understand the neurologically degraded acoustic signal, there is foundational evidence to support the use of perceptual learning paradigms in the development of a listener-based treatment program to address the intelligibility impairments. Primarily, a perceptual learning rehabilitation approach would aim to increase intelligibility through improved signal processing for the trained listener. While ultimately treatment that targets universal verbal interactions is the gold standard, any approach that improves communicative effectiveness affords significant clinical application. Listener training for the management of dysarthria may be particularly applicable in the following instances: when signal production does not improve with existing interventions; when speaker-oriented approaches are not recommended (e.g., in the case of motor neuron disease); or when co-occurring physical deficits limit the utility of augmentative or alternative approaches (e.g., communication devices, gesture, etc). Moreover, treatment that targets perceptual processes may serve as an adjunct to speakerorientated treatment to maximise performance outcomes with particular communication partners.

Our review of the previously published literature reveals that in order to advance this area of research, a systematic program of study grounded in current theories of perceptual learning and speech perception is needed. While a well-researched familiarization protocol with both familiar and unfamiliar listeners will ultimately be required, we consider the need to verify the presence or absence of learning, ascertain the source of learning, identify optimal learning conditions and determine the longevity of learning, using listeners naïve to dysarthric speech, as critical first steps in advancing this field and building a theoretical framework upon which future treatments can be developed. Finally, in this review the notion 
of exploiting perceptual learning for rehabilitative gain has been framed within the context of dysarthria management, yet the scope of application is potentially much broader. Bearing in mind that the source of learning may be differentially influenced by the nature of the acoustic degradation, treatments that target perceptual processes be may extended to any situation in which intelligibility is compromised (e.g., foreign-accented speech, Deaf speech, speech processed through cochlear implants, or synthesized speech systems). 


\section{REFERENCES}

Abercrombie, D. (1967). Elements of general phonetics. Chicago, IL: Aldine.

Ansel, B. M., \& Kent, R. D. (1992). Acoustic-phonetic contrasts and intelligibility in the dysarthria associated with mixed cerebral palsy. Journal of Speech and Hearing Research, 35, 296-308.

Black, J. W. (1957). Multiple-choice intelligibility tests. Journal of Speech and Hearing Disorders, 22, 213-235.

Bond, Z. S., \& Moore, T. J. (1994). A note on the acoustic-phonetic charateristics of inadvertently clear speech. Speech Communication, 14, 352-337.

Boothroyd, A. (1985). Evaluation of speech production of the hearing impaired: Some benefits of forced-choice testing. Journal of Speech and Hearing Research, 28, 185196.

Bradlow, A. R., \& Bent, T. (2008). Perceptual adaption to non-native speech. Cognition, 106, 707-729.

Clarke, C. M., \& Garrett, M. F. (2004). Rapid adaption to foreign-accented English. Journal of the Acoustical Society of America, 116, 3647-3658.

D'Innocenzo, J., Tjaden, K., \& Greenman, G. (2006). Intelligibility in dysarthria: Effects of listener familiarity and speaking condition. Clinical Linguistics and Phonetics, 20(9), 659-675.

Dahan, D., \& Mead, R. L. (2010). Context-conditioned generalization in adaptation to distorted speech. Journal of Experimental Psychology: Human Perception and Performance, 36(3), 704-728.

Davis, M. H., \& Johnsrude, I. S. (2007). Hearing speech sounds: Top-down influences on the interface between audition and speech perception. Journal of Hearing Research, 229, $132-147$. 
Davis, M. H., Johnsrude, I. S., Herrvais-Adelman, A., Taylor, K., \& McGettigan, C. (2005). Lexical information drives perceptual learning of distorted speech: Evidence from the comprehension of noise-vocoded sentences. Journal of Experimental Psychology: General, 134(2), 222-241.

Deane, K., Whurr, R., Playford, E. D., Ben-Shlomo, Y., \& Clarke, C. E. (2009). Speech and language therapy for dysarthria in Parkinson's disease: a comparison of techniques (Review). Cochrane Database of Systematic Reviews, (1), CD002814.

Duffy, J. R. (2005). Motor speech disorders: Substrates, differential diagnosis, and management (2nd ed.). St. Louis, MS: Elsevier Mosby.

Dupoux, E., \& Green, K. (1997). Perceptual adjustment to highly compressed speech: Effects of talker and rate changes. Journal of Experimental Psychology: Human Perception and Performance, 23(3), 914-927.

Eisner, F., \& McQueen, J. M. (2005). The specificity of perceptual learning in speech processing. Perception and Psychophysics, 67(2), 224-238.

Eisner, F., \& McQueen, J. M. (2006). Perceptual learning in speech: Stability over time. Journal of the Acoustical Society of America, 119, 1950-1953.

Fenn, K. M., Nusbaum, H. C., \& Margoliash, D. (2003). Consolidation during sleep of perceptual learning of spoken language. Nature (London), 425, 614-616.

Francis, A. L., \& Nusbaum, H. C. (2000). Effects of training on attention to acoustic cues. Perception and Psychophysics, 62, 1668-1680.

Francis, A. L., \& Nusbaum, H. C. (2009). Effects of intelligibility on working memory demand for speech perception. Attention, Perception, and Psychophysics, 71(6), $1360-1374$. 
Francis, A. L., Nusbaum, H. C., \& Fenn, K. (2007). Effects of training on the acousticphonetic representation of synthetic speech. Journal of Speech, Language, and Hearing Research, 50, 1445-1465.

Garcia, J. M., \& Cannito, M. P. (1996). Top down influences on the intelligibility of a dysarthric speaker: Addition of natural gestures and situational context. In D. Robin, K. M. Yorkston \& D. R. Beukelman (Eds.), Disorders of motor speech (pp. 67-87). Baltimore, MD: Paul H. Brookes.

Goldstone, R. (1998). Perceptual learning. Annual Review of Psychology, 49, 585-612.

Golomb, J. D., Peelle, J. E., \& Wingfield, A. (2007). Effects of stimulus variability and adult aging on adaption to time-compressed speech. Journal of the Acoustical Society of America, 121(3), 1701-1708.

Greenspan, S. L., Nusbaum, H. C., \& Pisoni, D. B. (1988). Perceptual learning of synthetic speech. Journal of Experimental Psychology: Learning, Memory, and Cognition, 14(3), 421-433.

Halle, M. (1985). Speculations about the representation of words in memory. New York, NY: Academic Press.

Hervais-Adelman, A., Davis, M. H., Johnsonrude, I. S., \& Carlyon, R. P. (2008). Perceptual learning of noise vocoded words: Effects of feedback and lexicality. Journal of Experimental Psychology: Human Perception and Performance, 34(2), 460-474.

Hervais-Adelman, A., Davis, M. H., Taylor, K., Johnsrude, I. S., \& Carlyon, R. P. (2011). Generalization of perceptual learning of vocoded speech. Journal of Experimental Psychology: Human Perception and Performance, 37(1), 283-295.

Hood, J. D., \& Poole, J. P. (1980). Influence of the speaker and other factors affecting speech intelligibility. Audiology, 19, 435-455. 
Hustad, K. C., \& Cahill, M. A. (2003). Effects of presentation mode and repeated familiarization on intelligibility of dysarthric speech. American Journal of SpeechLanguage Pathology, 12, 198-206.

Jusczyk, P. W., \& Luce, P. A. (2002). Speech perception and spoken word recognition: Past and present. Ear and Hearing, 23, 2-40.

Klasner, E. R., \& Yorkston, K. M. (2005). Speech intelligibility in ALS and HD dysarthria: The everyday listener's perspective. Journal of Medical Speech-Language Pathology, $13(2), 127-139$.

Kouider, S., \& Dupoux, E. (2005). Subliminal speech priming. Psychological Science, 16, 617-625.

Koul, R., \& Hester, K. (2006). Effects of repeated listening experiences on the recognition of synthetic speech by individuals with severe intellectual disabilities. Journal of Speech, Language, and Hearing Research, 49, 47-57.

Kraljic, T., \& Samuel, A. G. (2005). Perceptual learning for speech: Is there a return to normal? Cognitive Psychology, 51, 141-178.

Kraljic, T., \& Samuel, A. G. (2006). Generalization in perceptual learning for speech. Psychonomic Bulletin \& Review, 13(2), 262-268.

Liss, J. M. (2007). The role of speech perception in motor speech disorders. In G. Weismer (Ed.), Motor speech disorders: Essays for Ray Kent (pp. 187-219). San Diego, CA: Plural.

Liss, J. M., Spitzer, S. M., Caviness, J. N., \& Adler, C. (2002). The effects of familiarization on intelligibility and lexical segmentation in hypokinetic and ataxic dysarthria. Journal of the Acoustical Society of America, 112(6), 3022-3030. 
Lively, S. E., Pisoni, D. B., Yamada, R. A., Tohkura, Y. I., \& Yamada, T. (1994). Training Japanese listeners to identify English /r/ and /1/: III. Long-term retention of new phonetic categories. Journal of the Acoustical Society of America, 96(4), 2076-2087.

Loebach, J. L., Bent, T., \& Pisoni, D. B. (2008). Multiple routes to the perceptual learning of speech. Journal of the Acoustical Society of America, 124(1), 552-561.

Loebach, J. L., Pisoni, D. B., \& Svirsky, M. A. (2010). Effects of semantic context and feedback on perceptual learning of speech processed through an acoustic simulation of a cochlear implant. Journal of Experimental Psychology, 36(1), 224-234.

Logan, J. S., Lively, S. E., \& Pisoni, D. B. (1991). Training Japanese listeners to identify English /r/ and /1/: A first report. Journal of the Acoustical Society of America, 89, 874-886.

Mattys, S. L., \& Liss, J. M. (2008). On building models of spoken-word recognition: When there is as much to learn from natural "oddities" as artificial normality. Perception and Psychophysics, 70(7), 1235-1242.

Maye, J., Aslin, R. N., \& Tanenhaus, M. K. (2008). The weckud wetch of the wast: Lexical adaptation to a novel accent. Cognitive Science, 32, 543-562.

McClelland, J. L., \& Elman, J. L. (1986). The TRACE model of speech perception. Cognitive Psychology, 18, 1-86.

McGarr, N. S. (1983). The intelligibility of deaf speech to experienced and inexperienced listeners Journal of Speech and Hearing Research, 26, 451-458.

McGettigan, C., Rosen, S., \& Scott, S. K. (2008). Investigating the perception of noisevocoded speech - an individual differences approach. Journal of the Acoustical Society of America, 123(5), 3330-3330.

McQueen, J. M., Cutler, A., \& Norris, D. (2006). Phonological abstraction in the mental lexicon. Cognitive Science, 30, 1113-1126. 
McQueen, J. M., \& Mitterer, H. (2005). Lexically-driven perceptual adjustments of vowel categories. Proceedings of ISCA Workshop on Plasticity in Speech Perception, 233236.

Mehler, J., Sebastian-Galles, N., Altmann, G. T. M., Dupoux, E., Christophe, A., \& Pallier, C. (1993). Understanding compressed sentences: The role of rhythm and meaning. Annals of the New York Academy of Sciences, 682, 272-282.

Miller, J. L. (1981). Effects of speaking rate on segmental sidtinctions. In P. D. Eimas \& J. L. Miller (Eds.), Perspectives on the study of speech (pp. 39-74). Hillsdale, NJ: Erlbaum.

Miller, J. L., \& Liberman, A. M. (1979). Some effects of later-occuring information on the perception of stop consonant and semi-vowel. Perception and Psychophysics, 25(6), 457-465.

Norris, D., McQueen, J. M., \& Cutler, A. (2003). Perceptual learning in speech. Cognitive Psychology, 47, 204-238.

Nusbaum, H. C., \& Goodman, J. (1994). Learning to hear speech as spoken language. In H. C. Nusbaum \& J. Goodmann (Eds.), The development of speech perception: The transition from speech sounds to spoken words (pp. 299-338). Cambridge, MA: MIT Press.

Nusbaum, H. C., \& Lee, L. (1992). Learning to hear phonetic information. In Y. Tohkura, E. Vatikiotis-Bateson \& Y. Sagisaka (Eds.), Speech perception, production, and linguistic structure (pp. 265-274). Tokyo: Ohmsha.

Nygaard, L. C., \& Pisoni, D. B. (1998). Talker-specific learning in speech perception. Perception and Psychophysics, 60, 355-376.

Nygaard, L. C., Sommers, M. S., \& Pisoni, D. B. (1994). Speech perception as a talkercontingent process. Psychological Science, 5, 42-46. 
Pallier, C., Sebastian-Galles, N., Dupoux, E., \& Christophe, A. (1998). Perceptual adjustment to time-compressed speech: A cross-linguistic study. Memory and Cognition, 26, 844851.

Pisoni, D. B., Lively, S. E., \& Logan, J. S. (1994). Perceptual learning of nonnative speech contrasts: Implications for theories of speech perception. In H. C. Nusbaum \& J. Goodman (Eds.), The development of speech perception: The transition from speech sounds to spoken words (pp. 121-166). Cambridge, MA: MIT Press.

Reynolds, M. E., Isaacs-Duvall, C., \& Haddox, M. L. (2002). A comparison of learning curves in natural and synthesized speech comprehension. Journal of Speech, Language, and Hearing Research, 45, 802-810.

Reynolds, M. E., Isaacs-Duvall, C., Sheward, B., \& Rotter, M. (2000). Examination of the effects of listening practice on synthesized speech comprehension. Augmentative and Alternative Communication, 16, 250-259.

Rosen, S., Faulkner, A., \& Wilkinson, L. (1999). Adaptation by normal listeners to upward spectral shifts of speech: Implications for cochlear implants. Journal of the Acoustical Society of America, 106, 3629-3636.

Samuel, A. G., \& Kraljic, T. (2009). Perceptual learning for speech. Attention, Perception, \& Psychophysics, 71(6), 1207-1218.

Schwab, E. C., Nusbaum, H. C., \& Pisoni, D. B. (1985). Some effects of training on the perception of synthetic speech. Human Factors, 27, 395-408.

Sebastian-Galles, N., Dupoux, E., Costa, A., \& Mehler, J. (2000). Adaptation to timecompressed speech: Phonological determinants. Perception and Psychophysics, 62, 834-842. 
Sellars, C., Hughes, T., \& Langhorne, P. (2007). Speech and language therapy for dysarthria due to non-progressive brain damage. Cochrane Database of Systematic Reviews, (3), CD002088.

Spitzer, S. M., Liss, J. M., Caviness, J. N., \& Adler, C. (2000). An exploration of familiarization effects in the perception of hypokinetic and ataxic dysarthric speech. Journal of Medical Speech-Language Pathology, 8, 285-293.

Stacey, P. C., \& Summerfield, A. Q. (2007). Effectiveness of computer-based auditory training in improving the perception of noise-vocoded speech. Journal of the Acoustical Society of America, 121, 2923-2935.

Summerfield, Q., Haggard, M., Foster, J., \& Gray, S. (1984). Perceiving vowels from uniform spectra: Phonetic exploration of an auditory aftereffect. Perception and Psychophysics, 35, 203-213.

Tikofsky, R. S., \& Tikofsky, R. P. (1964). Intelligibility as a measure of dysarthric speech. Journal of Speech and Hearing Research, 7, 325-333.

Tjaden, K. K., \& Liss, J. M. (1995a). The role of listener familiarity in the perception of dysarthric speech. Clinical Linguistics and Phonetics, 9(2), 139-154.

Tjaden, K. K., \& Liss, J. M. (1995b). The influence of familiarity judgements of treated speech. American Journal of Speech-Language Pathology, 4, 39-48.

Watkins, A. (1981). Central, auditory mechanisms of perceptual compensation for spectralenvelope distortion. Journal of the Acoustical Society of America, 90, 2942-2955.

Weill, S. A. (2001). Foreign accented speech: Encoding and generalization. Journal of the Acoustical Society of America, 109, 2473 (A).

Yorkston, K. M., \& Beukelman, D. R. (1983). The influence of judge familiarization with the speaker on dysarthric speech intelligibility. In W. Berry (Ed.), Clinical dysarthria (pp. 155-164). Austin, TX: Pro-Ed. 
Yorkston, K. M., Beukelman, D. R., \& Bell, K. R. (1988). Clinical management of dysarthric speakers. Austin, TX: ProEd.

Yorkston, K. M., Dowden, P. A., \& Beukelman, D. R. (1992). Intelligibility as a tool in the clinical management of dysarthric speakers. In R. D. Kent (Ed.), Intelligibility in speech disorders: Theory, measurement and management (pp. 265-286). Amsterdam: John Benjamins. 
Table 1.1

Summary of Previously Published Studies on Perceptual Learning of Dysarthric Speech.

\begin{tabular}{|c|c|c|c|c|c|c|c|}
\hline Study & $\begin{array}{l}\text { Speaker } \\
\text { Participants }\end{array}$ & $\begin{array}{l}\text { Listeners } \\
\text { Participants }\end{array}$ & Experimental Groups & $\begin{array}{l}\text { Familiarization } \\
\text { Conditions }\end{array}$ & $\begin{array}{l}\text { Familiarization } \\
\text { Stimuli }\end{array}$ & $\begin{array}{l}\text { Transcription } \\
\text { Stimuli }\end{array}$ & Primary Findings \\
\hline $\begin{array}{l}\text { Yorkston \& } \\
\text { Beukelman } \\
(1983)\end{array}$ & $\begin{array}{l}\text { Nine individuals } \\
\text { with dysarthria of } \\
\text { varying severity } \\
\text { levels. }\end{array}$ & $\begin{array}{l}\text { Total of nine } \\
\text { individuals (five } \\
\text { speech } \\
\text { pathologists and } \\
\text { four student } \\
\text { clinicians). }\end{array}$ & $\begin{array}{l}\text { Assigned to one of } \\
\text { two familiarization } \\
\text { groups }(n=3) \text { : } \\
\text { passive or explicit. } \\
\text { Results compared } \\
\text { with a control group } \\
(n=3) \text { : no } \\
\text { familiarization. }\end{array}$ & $\begin{array}{l}\text { Passive or } \\
\text { explicit. }\end{array}$ & $\begin{array}{l}\text { Sentence list } \\
\text { presented three } \\
\text { times. }\end{array}$ & $\begin{array}{l}\text { Novel sentence } \\
\text { list. }\end{array}$ & $\begin{array}{l}\text { No significant difference in } \\
\text { intelligibility scores for familiarized } \\
\text { listeners compared to nonfamiliarized } \\
\text { listeners. }\end{array}$ \\
\hline $\begin{array}{l}\text { Garcia \& } \\
\text { Cannito } \\
(1996)\end{array}$ & $\begin{array}{l}\text { One individual } \\
\text { with severe } \\
\text { flaccid dysarthria } \\
\text { secondary to } \\
\text { stroke. }\end{array}$ & $\begin{array}{l}\text { Total of } 96 \\
\text { normal hearing } \\
\text { naive individuals. }\end{array}$ & $\begin{array}{l}\text { Assigned to one of } \\
\text { three groups }(n=32) \text { : } \\
\text { audio, visual, or } \\
\text { audio-visual, under } \\
\text { varying conditions: } \\
\text { familiarization, } \\
\text { gesture, predictive } \\
\text { stimuli, or situational } \\
\text { contexts.* }\end{array}$ & Passive. & $\begin{array}{l}\text { Short sample } \\
\text { conversational } \\
\text { speech. }\end{array}$ & $\begin{array}{l}16 \text { phrases: eight } \\
\text { "high" and eight } \\
\text { "low" predictive. }\end{array}$ & $\begin{array}{l}\text { No significant difference in } \\
\text { intelligibility scores for familiarized } \\
\text { listeners compared to nonfamiliarized } \\
\text { listeners. }\end{array}$ \\
\hline $\begin{array}{l}\text { Tjaden \& Liss } \\
\text { (1995a) }\end{array}$ & $\begin{array}{l}\text { One individual } \\
\text { with moderate- } \\
\text { severe mixed } \\
\text { spastic-ataxic } \\
\text { dysarthria } \\
\text { secondary to } \\
\text { Cerebral palsy. }\end{array}$ & $\begin{array}{l}\text { Total of } 30 \\
\text { normal hearing } \\
\text { naive individuals. }\end{array}$ & $\begin{array}{l}\text { Assigned to one of } \\
\text { two familiarization } \\
\text { groups }(n=10) \text { : word } \\
\text { list or paragraph } \\
\text { stimuli. Results } \\
\text { compared with a } \\
\text { control group }(n= \\
\text { 10): no } \\
\text { familiarization. }\end{array}$ & Explicit. & $\begin{array}{l}\text { Paragraph: } 12 \text { six- } \\
\text { word sentences } \\
\text { presented twice, or } \\
\text { Word list: } \\
\text { comprised of } 72 \\
\text { words in the } \\
\text { paragraph } \\
\text { presented twice in } \\
\text { random manner. }\end{array}$ & $\begin{array}{l}48 \text { phrases: } 16 \\
\text { questions; } 16 \\
\text { declaratives; } 16 \\
\text { imperatives. } \\
\text { Created by the } \\
\text { investigators to } \\
\text { sample a variety of } \\
\text { phonemes and } \\
\text { prosodic detail. }\end{array}$ & $\begin{array}{l}\text { Significantly higher intelligibility } \\
\text { scores for familiarized listeners } \\
\text { compared to nonfamiliarized listeners. } \\
\text { Average magnitude of difference of } \\
5 \% \text { (word list) and } 9 \% \text { (paragraph). } \\
\text { No significant difference in } \\
\text { intelligibility scores for listeners } \\
\text { familiarized with paragraph stimuli } \\
\text { compared to listeners familiarized with } \\
\text { word lists. }\end{array}$ \\
\hline
\end{tabular}




\begin{tabular}{|c|c|c|c|c|c|c|c|}
\hline $\begin{array}{l}\text { Tjaden \& Liss } \\
\text { (1995b) }\end{array}$ & $\begin{array}{l}\text { Same speaker as } \\
\text { per Tjaden \& } \\
\text { Liss (1995a). }\end{array}$ & $\begin{array}{l}\text { Total of } 30 \\
\text { normal hearing } \\
\text { naive individuals. }\end{array}$ & $\begin{array}{l}\text { Assigned to one of } \\
\text { two groups }(n=10) \text { : } \\
\text { treatment (speaker- } \\
\text { oriented breath-group } \\
\text { strategy) or treatment } \\
\text { + familiarization. } \\
\text { Results compared } \\
\text { with a control group } \\
\text { ( } n=10) \text { : no } \\
\text { familiarization with } \\
\text { habitual speech.* }\end{array}$ & Explicit. & $\begin{array}{l}12 \text { phrases: created } \\
\text { by the } \\
\text { investigators to } \\
\text { sample a variety of } \\
\text { phonemes } \\
\text { produced in } \\
\text { habitual speech. }\end{array}$ & $\begin{array}{l}48 \text { phrases: as per } \\
\text { Tjaden \& Liss } \\
\text { (1995a). }\end{array}$ & $\begin{array}{l}\text { Significantly higher intelligibility } \\
\text { scores for familiarized listeners } \\
\text { compared to nonfamiliarised listeners. } \\
\text { Average magnitude of difference of } \\
15 \% \text {. } \\
\text { Significantly higher intelligibility } \\
\text { scores for familiarized listeners } \\
\text { compared to the treatment group. } \\
\text { Average magnitude of difference of } \\
9 \% \text {. }\end{array}$ \\
\hline $\begin{array}{l}\text { Spitzer, Liss, } \\
\text { Caviness \& } \\
\text { Adler (2000) }\end{array}$ & $\begin{array}{l}\text { Twelve } \\
\text { individuals with a } \\
\text { moderate-severe } \\
\text { dysarthria: six } \\
\text { hypokinetic } \\
\text { dysarthria and six } \\
\text { ataxic dysarthria. }\end{array}$ & $\begin{array}{l}\text { Total of } 34 \\
\text { normal hearing } \\
\text { naive individuals. }\end{array}$ & $\begin{array}{l}\text { Assigned to one of } \\
\text { two familiarization } \\
\text { groups }(n=10) \text { : } \\
\text { hypokinetic speech or } \\
\text { ataxic speech. Results } \\
\text { compared with two } \\
\text { control groups }(n= \\
\text { 14): no } \\
\text { familiarization. }\end{array}$ & Explicit. & $\begin{array}{l}18 \text { phrases: three } \\
\text { per speaker. }\end{array}$ & $\begin{array}{l}60 \text { phrases: } 10 \text { per } \\
\text { speaker (produced } \\
\text { by same speech } \\
\text { type encountered } \\
\text { in familiarization). } \\
\text { Created by the } \\
\text { investigators to } \\
\text { enable error } \\
\text { patterns to be } \\
\text { analysed }\end{array}$ & $\begin{array}{l}\text { Significantly higher intelligibility } \\
\text { scores for familiarized listeners } \\
\text { compared to nonfamiliarized listeners. } \\
\text { Average magnitude of difference of } \\
10 \% \text { (hypokinetic) and } 17 \% \text { (ataxic). } \\
\text { Significantly less substitution errors } \\
\text { for listeners familiarized with ataxic } \\
\text { speech compared to nonfamiliarised } \\
\text { listeners. } \\
\text { No significant difference in } \\
\text { substitution errors for listeners } \\
\text { familiarized with hypokinetic speech } \\
\text { compared to nonfamiliarised listeners. }\end{array}$ \\
\hline $\begin{array}{l}\text { Liss, Spitzer, } \\
\text { Caviness \& } \\
\text { Adler, } \\
(2002)\end{array}$ & $\begin{array}{l}\text { Twelve } \\
\text { individuals with a } \\
\text { moderate-severe } \\
\text { dysarthria: six } \\
\text { hypokinetic } \\
\text { dysarthria and six } \\
\text { ataxic dysarthria. }\end{array}$ & $\begin{array}{l}\text { Total of } 80 \\
\text { normal hearing } \\
\text { naive individuals } \\
\text { and } 40 \text { normal } \\
\text { naive individuals. }\end{array}$ & $\begin{array}{l}\text { Assigned to one of } \\
\text { two familiarization } \\
\text { groups }(n=40) \text { : } \\
\text { hypokinetic or ataxic } \\
\text { stimuli. Results } \\
\text { compared with two } \\
\text { control groups }(n= \\
\text { 20): no } \\
\text { familiarization. }\end{array}$ & Explicit. & $\begin{array}{l}18 \text { phrases: three } \\
\text { per speaker. }\end{array}$ & $\begin{array}{l}60 \text { phrases: } 10 \text { per } \\
\text { speaker (one } \\
\text { dysarthria type) }+ \\
20 \text { phrases (other } \\
\text { dysarthria type) } \\
\text { i.e., } 60 \text { phrases } \\
\text { hypokinetic speech } \\
\text { followed by } 20 \\
\text { phrases ataxic } \\
\text { speech. }\end{array}$ & $\begin{array}{l}\text { Significantly higher intelligibility } \\
\text { scores for familiarized listeners } \\
\text { compared to nonfamiliarized listeners. } \\
\text { Average magnitude of difference of } \\
5 \% \text { (hypokinetic) and } 8 \% \text { (ataxic). } \\
\text { Subset of } 20 \text { low-intelligibility phrases } \\
\text { produced by same speech type } \\
\text { (specific familiarization) reflected } \\
\text { most robust improvements. Average } \\
\text { magnitude of difference of } 16 \%\end{array}$ \\
\hline
\end{tabular}


(hypokinetic) and 21\% (ataxic). Subset of 20 low-intelligibility phrases produced by other speech type (general familiarization) reflected significant improvements compared to nonfamiliarised listeners (although gains were significantly less than specific familiarization).

No significant difference in lexical boundary error patterns for familiarized listeners compared to nonfamiliarized listeners.

\begin{tabular}{|c|c|c|c|c|c|c|c|}
\hline $\begin{array}{l}\text { Hustad \& } \\
\text { Cahill (2003) }\end{array}$ & $\begin{array}{l}\text { Five individuals } \\
\text { with a mixed } \\
\text { dysarthria } \\
\text { secondary to } \\
\text { cerebral palsy: } \\
\text { mild } \\
\text { hyperkinetic, } \\
\text { mild spastic, mild } \\
\text { spastic, severe } \\
\text { spastic, and } \\
\text { severe mixed } \\
\text { spastic- } \\
\text { hyperkinetic. }\end{array}$ & $\begin{array}{l}\text { Total of } 100 \\
\text { normal hearing } \\
\text { naive individuals. }\end{array}$ & $\begin{array}{l}\text { Assigned to one of } 5 \\
\text { speaker groups }(n= \\
\text { 20): stimuli produced } \\
\text { by one of the five } \\
\text { speakers. } \\
\text { NB: intelligibility } \\
\text { scores compared } \\
\text { across trails. }\end{array}$ & Passive. & $\begin{array}{l}40 \text { HINT phrases: } \\
\text { produced by a } \\
\text { single speaker and } \\
\text { presented in four } \\
\text { sequential trials of } \\
10 \text { phrases. }\end{array}$ & $\begin{array}{l}\text { Familiarization } \\
\text { phrases transcribed } \\
\text { at time of } \\
\text { presentation. }\end{array}$ & $\begin{array}{l}\text { Significantly higher intelligibility } \\
\text { scores across four trials for all five } \\
\text { listener groups. Average magnitude of } \\
\text { difference of } 11 \% \text {. } \\
\text { Significant intelligibility gains for } \\
\text { severe dysarthria were realized only } \\
\text { between the first and third or first and } \\
\text { fourth trials. } \\
\text { Significant intelligibility gains for mild } \\
\text { dysarthria were realized only between } \\
\text { the first and second trials (no change } \\
\text { between subsequent adjacent trials). }\end{array}$ \\
\hline $\begin{array}{l}\text { D’Innocenzo, } \\
\text { Tjaden, \& } \\
\text { Greenman } \\
(2006)\end{array}$ & $\begin{array}{l}\text { One individual } \\
\text { with moderate } \\
\text { mixed spastic- } \\
\text { flaccid dysarthria } \\
\text { secondary to } \\
\text { traumatic brain } \\
\text { injury. }\end{array}$ & $\begin{array}{l}\text { Total of } 120 \\
\text { normal hearing } \\
\text { naive individuals. }\end{array}$ & $\begin{array}{l}\text { Assigned to one of } 12 \\
\text { groups }(n=10): \\
\text { various combinations } \\
\text { of three } \\
\text { familiarization } \\
\text { conditions (none, } \\
\text { word list, paragraph) } \\
\text { and four speaking } \\
\text { conditions.* }\end{array}$ & Explicit. & $\begin{array}{l}\text { Paragraph: } \\
\text { Grandfather } \\
\text { passage, or } \\
\text { Word list: } \\
\text { comprised of } \\
\text { words in the } \\
\text { Grandfather } \\
\text { passage presented } \\
\text { in random manner. }\end{array}$ & $\begin{array}{l}15 \text { AIDS } \\
\text { sentences. }\end{array}$ & $\begin{array}{l}\text { Significantly higher intelligibility } \\
\text { scores for listeners familiarized with } \\
\text { either word lists or paragraph stimuli, } \\
\text { as compared to unfamiliarized } \\
\text { listeners. Average magnitude of } \\
\text { difference of } 10 \% \text { (word list) and } 8 \% \\
\text { (paragraph). } \\
\text { No significant difference in } \\
\text { intelligibility scores of listeners }\end{array}$ \\
\hline
\end{tabular}


Note. *In studies where additional research questions are investigated, only relevant information is reported; "passive" conditions refer to familiarization with the dysarthric signal; "explicit" conditions refer to familiarization with the dysarthric signal and supplementary written information of the auditory targets. Intelligibility scores = word recognition accuracy; "naive" refers to listeners with minimal or no prior experience with dysarthria; AIDS = Assessment of Intelligibility of Dysarthric Speech (Yorkston \& Beukelman, 1981); HINT = Hearing in Noise Test (Nilsson, Soli, \& Sullivan, 1994). 